\title{
Familial pneumothoraces and bullae
}

\author{
G. J. GIBSON \\ From the Department of Medicine, Hammersmith Hospital, Du Cane Road, London W12 OHS
}

Gibson, G. J. (1977). Thorax, 32, 88-90. Familial pneumothoraces and bullae. The cases of three sisters who presented with spontaneous pneumothoraces are described. In two of the patients large bullae were clearly demonstrable. No recognisable associations of bullae or pneumothorax were present and there was no evidence of generalised emphysema. The cases suggest a familial predisposition to the development of bullae in otherwise apparently healthy lungs.

The classification of bullae usually depends on whether the non-bullous lung is healthy or emphysematous (Ogilvie and Catterall, 1959). Familial emphysema, such as occurs with Marfan's syndrome (Bolande and Tucker, 1964) and $\alpha_{1}$ antitrypsin deficiency (Eriksson, 1965) may be accompanied by bullae, but bullae occurring in otherwise normal lungs are thought to be acquired and degenerative (Belcher and Siddons, 1954), probably following infection (Almeyda, 1949; Ogilvie and Catterall, 1959).

I here report the cases of three sisters who presented with spontaneous pneumothorax; in two of the patients multiple bullae were present but no predisposing factors were recognisable and there was no functional evidence of widespread emphysema.

\section{Case reports}

The patients presented to the Chest Clinic at Hammersmith Hospital between 1947 and 1970 with spontaneous pneumothoraces (Table 1). None had any features of Marfan's syndrome and blood levels of $\alpha_{1}$ antitrypsin were normal. The patients' father had also suffered two pneumothoraces but no further details are available.

Patient 1, a non-smoker, first presented at the age of 28 with a right pneumothorax. Because of slow resolution, thoracoscopy was performed and showed a large bulla, $4 \mathrm{~cm}$ in diameter, arisin from the upper lobe. Camphorated oil was in stilled and full expansion followed; a subsequent chest radiograph was described as normal. A lef sided pneumothorax developed in 1960 and, bॄ్ cause of failure of re-expansion after seven months, a further instillation of camphorated of was performed with full resolution. In 1971, th patient again noticed dyspnoea and became aware of a clicking sensation in the chest. The radiog graph (Fig. 1) showed probable localised pneumo. thorax at the right base with evidence of furthe bullae in the same area and also in the right uppes zone and probably the left lower zone. The radiog graphic appearance has not changed over the subsequent five years. Pulmonary function (Table 2) shows a small vital capacity (VC) and a large residual volume (RV) (measured plethysmographis cally) with a slightly reduced forced expirator ratio $\left(\mathrm{FEV}_{1} / \mathrm{VC}\right)$. The carbon monoxide transf factor (DLco) was well preserved in relation the volume of functioning lung, ie, the transfep of $\mathrm{CO}$ per litre alveolar volume (KCo) was normal.

Patient 2 first presented with a left pneuma thorax at the age of 32 when thoracoscopy showeed

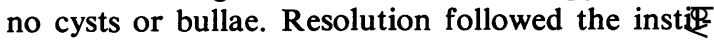

Table 1 Details of patients

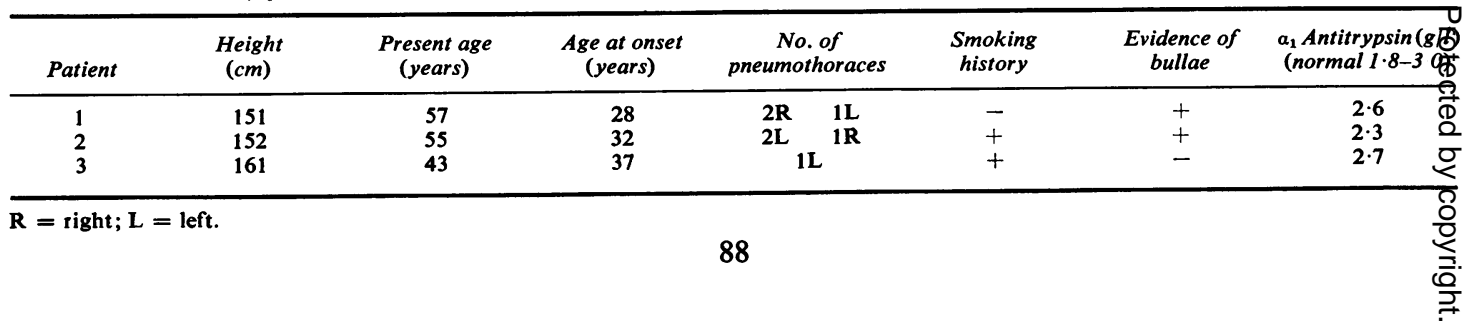




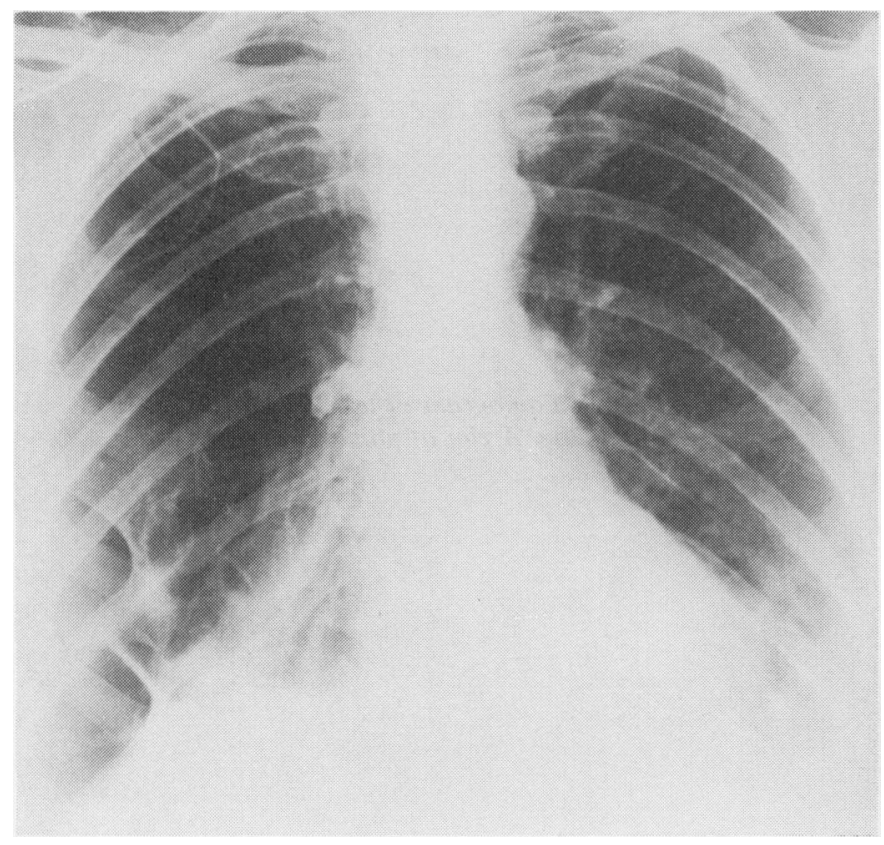

Fig. 1 Patient 1. Chest radiograph showing extensive bullae; there is probably a pneumothorax at the right base.

Table 2 Pulmonary function

\begin{tabular}{|c|c|c|c|c|c|c|c|c|c|c|c|c|c|}
\hline \multirow[b]{2}{*}{ Patient } & \multicolumn{2}{|c|}{$F E V_{1}$} & \multicolumn{2}{|c|}{$V C$} & \multirow{2}{*}{$\begin{array}{c}F E V_{1} / V C \\
\%\end{array}$} & \multicolumn{2}{|c|}{$R V^{1}$} & \multicolumn{2}{|c|}{$T L C^{1}$} & \multicolumn{2}{|c|}{ DLco $^{2}$} & \multicolumn{2}{|c|}{$\mathrm{KCO}^{2}$} \\
\hline & Litres & $\begin{array}{c}\% \\
\text { Predicted }\end{array}$ & Litres & $\begin{array}{c}\% \\
\text { Predicted }\end{array}$ & & Litres & $\begin{array}{c}\% \\
\text { Predicted }\end{array}$ & Litres & $\begin{array}{c}\% \\
\text { Predicted }\end{array}$ & $\begin{array}{l}\mathrm{mmol} \\
\min ^{-1} \\
k \mathrm{~Pa}^{-1}\end{array}$ & $\begin{array}{c}\% \\
\text { Predicted }\end{array}$ & $\begin{array}{l}\mathrm{mmol} \\
\mathrm{min}^{-1} \\
\mathrm{kPa}^{-1} \\
\mathrm{l}^{-1}\end{array}$ & $\begin{array}{c}\% \\
\text { Predicted }\end{array}$ \\
\hline 1 & 0.9 & 45 & $1 \cdot 3$ & 54 & 69 & $2 \cdot 7$ & 180 & 4.0 & 100 & $5 \cdot 1$ & 74 & 1.5 & 83 \\
\hline 2 & 1.5 & 75 & $2 \cdot 2$ & 96 & 66 & 1.5 & 100 & $3 \cdot 7$ & 95 & 6.8 & 98 & 1.8 & 105 \\
\hline 3 & 3.0 & 115 & 3.8 & 115 & 79 & 2.0 & 121 & $5 \cdot 8$ & 117 & $6 \cdot 6$ & 79 & $1 \cdot 2$ & 67 \\
\hline
\end{tabular}

${ }^{1}$ By whole-body plethysmography (DuBois et al., 1956).

'By single-breath method (Ogilvie et al., 1957).

lation of camphorated oil. Four years later a pneumothorax occurred on the opposite side and thoracoscopy showed several thin-walled bullae arising from the middle lobe, the largest $3 \mathrm{~cm}$ in diameter. Resolution followed application of silver nitrate. During the next two years bullae at the left base became visible in the radiograph and a further left pneumothorax followed. A tomographic cut of the left lower zone showed extensive bullae (Fig. 2). Because of slow resolution talc was instilled into the pleural cavity and no subsequent pneumothoraces occurred. Fifteen years later the patient remains well and a bulla is still visible at the left base. Pulmonary function (Table 2) shows only mild airways obstruction.

Patient 3 presented with a left pneumothorax at the age of 37 ; gradual re-expansion occurred spontaneously over several months and no bullae were visible. Pulmonary function showed a mild reduction of $\mathrm{Kco}$.

\section{Discussion}

The patients were unlike the typical patient with spontaneous pneumothorax in that all were female, their height was not above average, the age of onset was in the third or fourth decade, and re-expansion of the lung was usually slow. Although bullae were visualised in only two of the patients, it seems likely that each event was due to rupture of a bulla. The patients had none of the recognised familial associations of bullae or pneumothorax. Bullae with $\alpha_{1}$ antitrypsin deficiency and Marfan's syndrome are usually part of generalised emphysema but the relative preservation of carbon monoxide transfer factor and 


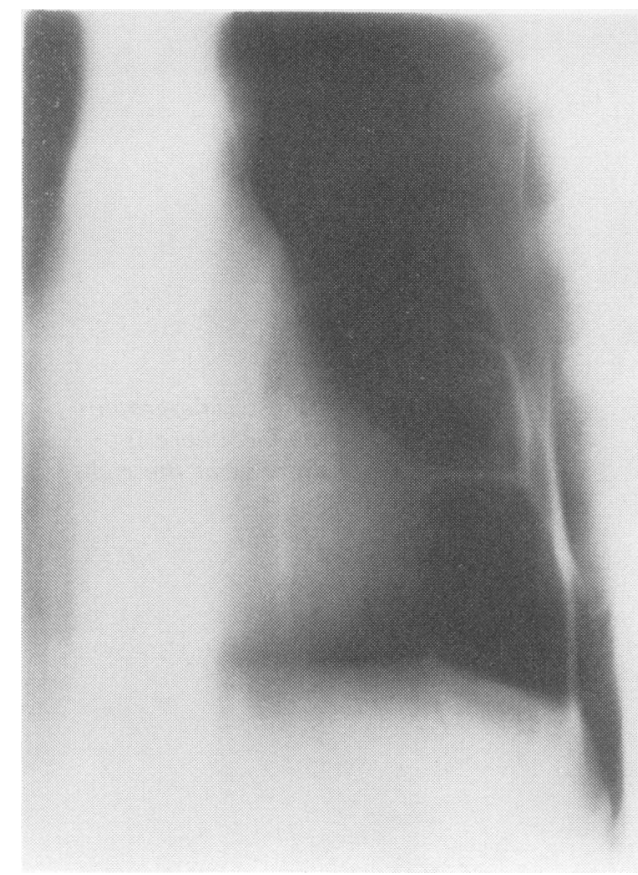

Fig. 2 Patient 2. Tomogram of left lower zone showing large bullae. A rim of pneumothorax is present. absence of hyperinflation in these patients suggests virtually normal function of the non-bullous lung. The minor abnormalities of pulmonary function in patients 2 and 3 might be due to cigarette smoking; patient 1 was, however, a lifelong nonsmoker and her high residual volume and slightly reduced forced expiratory ratio are probably a direct consequence of the bullae and resulting distortion of the normal anatomy.

The familial association described here suggests a predisposition to the development of bullae, and hereditary factors may be involved in their pathogenesis even in the absence of generalised emphysema.

I am grateful to Drs. P. Stradling and N. B. Pride for helpful discussion and permission to publish details of the patients.

\section{References}

Almeyda, J. (1949). Solitary cystic disease of the lung. British Journal of Tuberculosis, 43, 74-84.

Belcher, J. R. and Siddons, A. H. M. (1954). Aircontaining cysts of the lung. Thorax, 9, 38-45.
Bolande, R. P. and Tucker, A. S. (1964). Pulmonary emphysema and other cardio-respiratory lesions part of the Marfan abiotrophy. Pediatrics, 33. 356-366.

DuBois, A. B., Botelho, S. Y., Bedell, G. N., Marshah; R., and Comroe, J. H., Jr. (1956). A rapid plethy mographic method for measuring thoracic ga volume: a comparison with a nitrogen wash-out method for measuring functional residual capaci in normal subjects. Journal of Clinical Investigation. 35, 322-326.

Eriksson, S. (1965). Studies in alpha ${ }_{1}$ antitrypsi deficiency. Acta Medica Scandinavica, Supplement 432.

Ogilvie, C. and Catterall, M. (1959). Patterns of di turbed lung function in patients with emphysema: tous bullae. Thorax, 14, 216-224.

Ogilvie, C. M., Forster, R. E., Blakemore, W. $s$ and Morton, J. W. (1957). A standardized breat\$ holding technique for the clinical measurement ${ }_{0}$ the diffusing capacity of the lung for carbon more oxide. Journal of Clinical Investigation, 36, 1-17

Requests for reprints to: Dr. G. J. Gibson, Departo ment of Medicine, Hammersmith Hospital, Du Cane Road, London W12 OHS. 